KEYNOTE ADDRESS

\title{
ORGANIZING TO RESPOND TO EXTERNAL RESEARCH OPPORTUNITIES: DIMENSIONS OF CONCERN FOR UNIVERSITY COLLECTIVE ACTION
}

\author{
Michael M. Crow \\ Vice Provost, Columbia University \\ Professor of Science and Technology Policy
}

\section{Origins of the Research University}

The history behind the development of the "research university" is long and rich. We can see the first signs of such an institution in the establishment of the University of Bologna and the University of Paris in the 1300s. While Bologna was established primarily as a professional school (law and medicine) and Paris grew out of ecclesiastical schools of the $12^{\text {th }}$ century, after the Great Schism of 1378 these and other institutions came to encompass faculties of art, theology, law and medicine.

These institutions were important organizational innovations for the time, but they did not play a crucial role in the advance of knowledge as time went on, particularly during the $17^{\text {th }}$ and $18^{\text {th }}$ centuries. Retaining narrow and antiquated curricula, these institutions actually opposed the ideologies of the Enlightenment. Instead, scientific societies and academies developed to fill this void and to advance science. Through the $17^{\text {th }}$ century, such organization played a critical role in self-sustaining science. The ideal of this model can be found in the Royal Society and the Académie Royale des Sciences. Hundreds of such societies emerged of various size and importance. From this, an international community of scientists began to develop.

After more than two centuries of atrophy, the university as an institution began a revitalization as it faced a more desirable political and religious environment, and as it absorbed the norms of open science developed by the academies. It is out of this revitalization that the new models of teaching and research developed in Germany, England and France.

And, while the elite American colleges were built originally to educate gentlemen in the ways of theology, languages and the classics, they too were soon subjected to the powerful influence of this international scientific community.

\section{The Nineteenth Century}

Before 1850, we saw a number of different strands of research university take hold; each peculiar to its own national history. England had Oxford and Cambridge, but 
it also had the Royal Institution of London which served as a center for both fundamental and applied scientific laboratory work in the Baconian tradition. France, under Napoleon, developed a suite of Ecoles that were designed to support the development of a strong engineering class and bureaucratic class. The German research universities grew up as full bodied institutions encompassing the literature and philosophy of the Romantic period and strong theoretical and empirical work in the sciences. And, by this time, other European science centers had emerged.

In America, we had little in the way of "research" going on during this period. Westpoint, as America's military academy, was a center of engineering excellence, but science had no place. Rensellaer Polytechnic was established in the 1820 s modeled on the French Ecoles, but it did not embrace the sciences fully until it reorganized just before 1850. By the 1850s, some "scientific schools" were established within more traditional American colleges like Harvard, Yale and Columbia. These schools sewed the seeds for their later transformation into research universities, but the scientific schools were hardly welcomed into the institutions.

By the Mid-1870s, Land Grant universities had been established in nearly every state under the Morrill Act of 1863 . Also, aspects of the German research university transferred to America with the establishment of Johns Hopkins in 1876. The model of the scientific school had spread throughout American colleges, and elective tracks had evolved allowing students to select concentrations in the sciences.

At the same time, Germany's research universities had risen to clear prominence in chemistry, physics and agricultural sciences.

By the 1890's, the American research university community had evolved into a structure much like today's. At that time there were 15 research universities. Illinois, Michigan, Minnesota, Wisconsin, and California developed state universities that had scientific and engineering research at their core. Columbia, Harvard, Penn, Princeton, and Yale had successfully evolved from being traditional elite colleges specializing in languages, religion and the classics into developing centers of scientific and engineering research. And Johns Hopkins, Stanford, and University of Chicago-each established as a research university-were joined by MIT and Cornell-with slightly different histories-to become the pack of more recently established schools focused on research.

\section{World War II and Beyond}

Immediately after World War II, a slightly different structure emerged in the American research university community. Illinois, Michigan, Minnesota, Wisconsin, and California continued as the public research universities. But other land-grants such as Iowa State, Penn State, and North Carolina State developed into institutions with considerable research capacities. Out of the traditional elite colleges and the newer research universities, Columbia, Harvard, Stanford, University of Chicago and Johns Hopkins emerged as the central private research universities. And MIT and the new California Technical took on a distinctive, more narrow character as major technical 
institutes. As such, one can discern not one American research university model, but several.

But this immediate postwar pattern did not keep the system from evolving. Indeed, massive postwar science funding, in tandem with considerable institutional entrepreneurialism, led to the development of entirely new institutions of research, such as, University of California at San Diego, Arizona State, State University of New York at Stony Brook, and Duke. Still others fit into this category.

In sum, many different brands of research university have evolved with distinctly different competencies in terms of types and fields of research. It is this variety that has made our national innovation system so robust.

\section{The Changing Composition of American Industry}

When American research universities were taking hold in the 1890s, the state of the world was very different. The state of our technological resources and know-how was very different. At that time, science was only a major input for a select set of industries in America, namely electrification, telegraphy/telephony, and in chemical inputs/processes for agriculture and steel. This list of dominant, vital industries illustrates this situation: machine tools, firearms, clocks, sewing machines, hardware, agricultural implements, bicycles, steel, electrification, telegraphy/telephony.

A century later, we see a distinctly different pattern. Science underpins innovation in virtually any major industry you can imagine. Microelectronics, biotechnology, advanced materials, telecommunications, CNC machine tools, civilian aircraft, computers (hardware and software). The list can be extended for some time. The evolution of these industries and associated fields of technology has much to do with the rise of the institutions of science a century before. Also, in many cases, these industries and technologies owe much to ongoing federal commitment to research performed in these and other institutions.

And, if we look into the crystal ball, we see emerging areas of technology that we can currently only imagine. And, they cannot even be imagined apart from major university research capacities in a range of related areas.

\section{The Technology Development Continuum}

In 1945, Vannevar Bush's famous report Science The Endless Frontier articulated a linear model of innovation wherein basic research advances at universities fueled applied research and development at firms. We see this here in the technology development continuum. While Bush had his reasons for characterizing the process of innovation in such a simplified way, his simplification missed several critical aspects of the nature of our research system. 
First, as Donald Stokes pointed out in his book Pasteur's Quadrant, the distinction made in the linear model between basic and applied is not always useful. Stokes focused on a mode of fundamental scientific inquiry conducted by a research inspired by considerations of use, as did Pasteur. The distinction becomes even less useful when one considers a problem that Lewis Branscomb has noted-that fundamental technology development is no less fundamental than basic science, yet it has no place in the linear model.

In short, the linear model breaks down upon consideration of how innovation actually occurs. Moreover, the role it assigns to universities is contrary to that which history demonstrates. Universities have been involved in many aspects of scientific advance and technological change, only one of which is assigned to it in the linear model. The variety of universities in the American national innovation system have been involved in many different scientific and engineering activities depending on the industry, field of technology and the various social commitments made to these areas.

\section{The Range of Research Types}

If you take the standard set of departments at your top tier research university, you find a variety of science and engineering departments doing a wide array of activities. The core sciences are represented along with a large number of engineering disciplines.

With America's historic commitment to supporting agriculture through education and research, we find that many universities, particularly the land-grants, have developed an additional level of agriculture-specific disciplines. These disciplines are no less fundamental but are very applied in many ways. They are intimately related to areas of university research that are typically considered more in line with the model of a "research university." Where would entomology be without biology? And where would soil sciences be without chemistry? In this case, universities have housed a wide range of research.

Again, we see this phenomenon in our academic medical centers. They include an additional level of research specific to providing for a healthy population. The basic bio-sciences, clinical departments and medicine departments are intimately related to the standard university basic sciences and engineering disciplines. They are no less fundamental, but are often highly applied to particular problems. But, where do they lie on the linear model?

In the example of information technology, we see a set of disciplines that owe much to the rise of one specific technology-computers. Yet, they also owe much to the bodies of knowledge developed by the traditional university disciplines. Our ability to encode information in electronic signals, and then to process and compute these signals is a skill that has drawn upon scientific and engineering expertise in many fields, from physical chemistry and applied mathematics to applied physics. This work is highly 
applied, yet often quite fundamental. And, universities operate at the cutting edge, time and time again.

The case of development, both urban and not-so-urban development is almost entirely about applied work. However, universities have been involved in research into these matters for over a century. Research into the design and fabrication of new infrastructure has seen significant university involvement for quite some time. Urban planning, while not a science, has been a field of university research with great impact. Now, with the rise of information technology, new techniques in planning information systems are being pioneered in university environments. All of this is applied, but universities have been significant and valuable players.

\section{Parallel Process Model of Technology Development}

There are simple alternatives to the linear model that provide us with a more robust understanding of the tandem processes of scientific advance and technological change. This model demonstrates the two directional flow. It also demonstrates some of the complexities that exist beyond basic and applied research. In this model we do not even attribute one or another aspect to different institutional players or firms, because we know from our empirical studies that different areas of technology and different industries enjoy very different configurations of institutional and industrial actors. The research and development division of labor can vary widely.

While universities develop many different types of knowledge products embodied in innovations, articles and individuals, it is firms that are the organizations that have the comparative advantage in "making airplanes," "designing microprocessors," and otherwise producing goods and providing services. With their senses trained on particular markets and their competencies honed to particular niches, firms are the locus of much learning related to the advance of particular goods and services. But, their continued vitality often depends on the rejuvenating forces offered by university knowledge generation.

A range of university-industry interactions sustain long run technological change. Some are direct such as the diffusion of trained scientific and technical personnel embodying pertinent knowledge. Others are indirect such as the development of instrumentation and methodologies that are absorbed into industrial practice. Still others are vague such as access firms might have to university based knowledge networks for both infrastructural knowledge or an interdisciplinary mix of university researchers capable of solving complex problems. These interactions differ by fields of science, areas of technology, and industry. Yet, universities play critical roles in supporting innovation through basic science and a wide array of other modes of research. 


\section{Designing University-Industry Interfaces}

The practical impact of various types of university-industry interfaces can vary by: 1) proximity, 2) the composition of science and engineering graduates, 3) the match between industry and university strengths, and 4) the institutions developed to mediate between universities and industries. These factors must be considered as one designs university-industry interfaces. If one hopes to use such interactions to facilitate particular impacts, one must understand the relationship that each of these dimensions has to their institutional design.

When trying to understand how to better organize your universities as institutions committed to catalyzing progress, you must design your institutions while aware of these dimensions. But, most important, you must decide what kind of university you want and the kind of impacts you would like to have. There are many options and a university can serve many purposes depending on how it is designed.

\section{Freeman's "Three Phases" of Science Policy}

Christopher Freeman has described the history of science and technology policy as one that can be understood in three phases. In his view, science and technology (S\&T) policies often begin directed toward military purposes. As some nations progress, they begin to evolve a commercially-centered S\&T policy, though it is usually built in addition to the original military S\&T resources. And, for Freeman, some countries are beginning to evolve comprehensive S\&T policies which focus in on a broader array of quality of life issues that can be tackled through science and technology.

Most would acknowledge that America exists somewhere in the second phase, though many openly object to such targeting of resources. And, most would contend that a broader focus on the quality of life exists only in America's distant future.

The accomplishment of this third phase will depend heavily on issues of institutional design.

\section{Roger Noll's Thesis}

Roger Noll believes that the decline in the growth of the federal commitment to science will lead to some lean years in university research. The impact, in his view, will be that these declining real dollars will favor the elite universities and that second tier institutions will be forced to seek industry funding to maintain their enterprises. Noll sees this as a negative force, with the implicit assumptions that universities best do basic research and that industry sponsored research will be more applied in nature. Perhaps. But, Noll fails to understand that universities do a wide array of different types of research and can legitimately contribute to many applied goals. It is the shape and nature 
of these university-industry interactions that will condition the qualitative characteristics of the outputs of these interactions.

\section{General Environment and Interactions}

Many aspects of a university's environment are advantageous if the university is entrepreneurial enough. There are options in how a university can evolve. However, if universities feel constrained to adhere to some model of an "American Research University" many of these options are overlooked. Universities have never adhered to a single form and it is often the relationships of universities to other segments of our society that distinguish them from each other. While this external environment is complex, it offers much potential for crafting universities with significant impacts.

\section{How Do You Think about Organizing Collectively?}

From all this, it seems that there are a series of questions one must ask when thinking about how universities might think about organizing collectively to seize opportunities in a changing environment.

What is the substantive vision?

What niche is each institution willing to fill?

What complementarities exist that could be exploited?

What new governance and business models will permit this?

How can business stakeholders be integrated into priority setting?

What will the new federal-state-institution relationship look like?

Only when we are willing to face these questions will we be ready to seize the opportunities posed by this new and challenging era. 